\title{
Arthroscopic Treatment for Intraosseous Ganglion Cyst of Carpal Bone Combined With Occult Wrist Instability
}

\section{Gang Zhao ( $\nabla$ zhaogangmd@suda.edu.cn )}

Wuxi 9th People's Hospital Affiliated to Soochow University https://orcid.org/0000-0002-1308-4915

Shanchun Tao

Shangyu People's Hospital

Jingyi Mi

Wuxi Ninth People's Hospital Affiliated to Soochow University

Qun Yao

Wuxi Ninth people's Hospital Affiliated to Soochow University

\section{Research article}

Keywords: Intraosseous ganglion cyst, arthroscopy, thermal shrinkage, wrist instability

Posted Date: December 18th, 2020

DOI: https://doi.org/10.21203/rs.3.rs-129860/v1

License: (0) (i) This work is licensed under a Creative Commons Attribution 4.0 International License. Read Full License 


\section{Abstract}

Background: Intraosseous ganglion cysts (IOGs) of the carpal bone are uncommon tumors that may represent rare causes of chronic wrist pain. Arthroscopic resection has been described in isolated symptomatic cases as a feasible technique; however, there is no published study investigating this technique in an unstable wrist. We aimed to study the outcome of arthroscopic lesion resection combined with intercarpal ligament thermal shrinkage for the IGOs in the wrists with occult instability.

Methods: Fourteen patients from our hospital database between 2013 and 2015 who had IOGs combined with occult carpal instability were retrospectively reviewed. Diagnosis was exclusively established based on persistent wrist pain and functional limitation before surgery. The IOGs were removed under arthroscope, and bone grafting was performed accordingly dependent on the sizes and locations of the lesion. The lax intercarpal ligaments were tightened by radiofrequency shrinkage. Results were analyzed for demographic data and functional outcomes.

Results: At a mean follow-up of 27 months, all patients were satisfied with pain relief and the patients' grip power improved. The pre- and postoperative range of motion of the affected wrist had no significant difference. Radiologically, cyst recurrence and joint instability development were not observed. The postoperative function of the wrists significantly improved based on the Mayo Wrist Score and Patient-rated Wrist Evaluation score.

Conclusions: For IOGs of carpal bones in the wrist with occult instability, arthroscopic treatment, including cyst resection and ligament thermal shrinkage, was an effective way to improve pain and function of the effected wrist.

\section{Background}

Intraosseous ganglion cysts (IOGs) are one of the common benign bone tumors within the carpal bones and are often found by incident on radiographs obtained for other purposes. ${ }^{[1]}$ Most of these lesions are observed in the proximal row carpus, specifically in the lunate and rarely in the capitate and other distal row carpal bones. Most individuals with these lesions are asymptomatic, but chronic wrist pain and functional incapacitation present in a few cases, typically due to the pathologic fracture. ${ }^{[2]}$ Furthermore, the wrist is at risk of carpal instability when the cysts are located at the border of the carpal bone where the ligament attached. Furthermore, according to previous studies, soft tissue ganglion cysts, which are highly associated with interosseous laxities and joint instability, are coexist in a certain proportion of the patients with IOGs. ${ }^{[3,4]}$ Besides, the trauma history can be found in some IGOs cases, which may be the cause of the intercarpal ligament injury leading the joint instability. Therefore, the carpal IGOs combined with wrist instability should be considered as a special type of intra-articular lesion, which is associated with wrist pain, weakness and dysfunction.

Surgical treatment for IOGs comprises curettage of the cysts with or without a bone graft. ${ }^{[5-7]}$ Traditional operation with open surgical approach may lead to some complications such as joint stiffness and vascular disturbances of the carpal bones. ${ }^{[8]}$ Considering the advancement in wrist arthroscopy, a minimally invasive technique of arthroscopically assisted debridement and bone grafting has been achieved for the carpal IOGs, during which the interosseous ligaments of the wrist can be disposed in one stage using radiofrequency shrinkage, which is a classical way to treat the occult instability of intercarpal joint through the capsule and ligament contraction. ${ }^{[9-11]}$ This study aimed to evaluate the results of arthroscopic lesion resection combined with intercarpal ligament thermal shrinkage for the IGOs in the wrists with occult instability.

\section{Methods}

\section{Patients}

We identified a total of 14 patients ( 11 women, 3 men) who had symptomatic IOGs and occult carpal instability of the wrist and underwent arthroscopic surgery between 2013 and 2015 with the approval of the institutional review board of our hospital. Clinical data were collected from the patients' medical records. All included patients had participated in the final follow-up evaluation after we invited them for both physical and imaging examinations. Surgical indications were severe or persistent pain during wrist motion, limited range of motion (ROM), and reduced grip strength with a failure of a trial of splints and nonsteroidal antiinflammatory drugs for at least 3 months. None of them recalled any traumatic events before symptoms emerge.

Page $2 / 14$ 
Preoperative physical examination was carefully performed for each case to determinate the diagnosis. Local tenderness at the involved carpal bones and on the affected adjacent interosseous ligaments that matched with the imaging findings was observed. Pain was always more evident when passive stress test (e.g., extreme flexion, extension, radial deviation, and ulnar deviation) was performed. A positive Watson's test or a Ballottement test was the basis for the diagnosis of scapholunate or lunotriquetral instability, which was typically manifested pain rather than severe tossing. The wrists were evaluated before and after surgery including pain level, active motion, and grip strength. Pain level was recorded using a visual analog scale (VAS). The ROM of both wrist joints was measured using a goniometer. Grip strength was measured using a Jamar hand dynamometer (Lafayette Instrument Company, USA). Wrist function was evaluated using the Mayo Wrist Score (MWS) and Disabilities of the Arm, Shoulder, and Hand (DASH) questionnaire.

Radiographic evaluation was performed routinely before surgery. Plain film radiography and computed tomography (CT) scan usually revealed an eccentric radiolucent lesion with a thin sclerotic margin (Fig. 1). Pathologic fractures were observed in some patients due to ruptured cortices, possibly causing the symptom. Magnetic resonance imaging (MRI) revealed that the lesions were hypointense in T1-weighted and hyperintense in T2-weighted images. It's worth noting that a soft tissue ganglion cyst case may coexist with IOG (Fig. 2). Moreover, preoperative imaging evaluation would not be complete until the differential diagnoses were established including old fractures, avascular necrosis, and ulnar impingement syndrome.

\section{Surgical technique}

The procedure was performed with the patients in the supine position, with their shoulders abducted at $90^{\circ}$ and their elbows flexed at $90^{\circ}$. The forearms were suspended on Chinese finger traps with 4 to $6 \mathrm{~kg}$ of countertraction. Routine wrist arthroscopic examination was performed via the 3-4 and midcarpal ulnar (MCU) portals. Most frequently, an IOG was hardly detected due to the normal bone appearance. Hence, the following strategies should be considered to locate the lesion. Firstly, a careful and thorough analysis of the three-dimensional imaging should be performed such as CT and MRI, which could provide the gross location of the lesion. Secondly, characteristic signs indicating the lesion could be found under arthroscope, including crack, denudation or soft surface of the cartilage, pathologic fracture, and local synovitis. Thirdly, intraoperative X-ray is considered beneficial with the anteroposterior and lateral view assisted by a metal needle. To facilitate cyst excision, different individual portals were created (6R or 4-5 portals for the IOGs in the lunate, $6 \mathrm{U}$ or volar ulnar portal for the triquetrum, 3-4 portals or midcarpal radial [MCR] portal for the scaphoid). The interosseous ligaments related to the affected carpal bone and the instability of the intercarpal joint must be assessed according to the arthroscopic classification system described by Geissler et al. ${ }^{[12]}$ through the MCR or MCU portal (Fig. 3). Among this case series, attenuation and elongation were detected without ligament rupture, and mild instability of the intercarpal joints was confirmed without incongruency or step-off of carpal alignment.

Before the treatment of the IOGs, the coexisting soft tissue ganglia cysts were excised using the method described by Osterman and Raphael ${ }^{[13]}$. Although the stalk of the ganglia cyst might not be observed under arthroscopic visualization, pressing the cyst body on the wrist surface was considered beneficial. The entire ganglion cyst and stalk combined with a 1-cm-diameter area of the capsule was excised to prevent the recurrence.

After the IOG was exactly located using the abovementioned strategies, a hole was drilled using a 1.5-mm Kirschner wire at the nonload-bearing area (Fig. 4). The direction was toward the inner lesion, and the depth of the hole was determined according to the preoperative imaging and intraoperative fluoroscopy. The hole was subsequently enlarged using a 3.0-mm cannulated drill, from where the white and flocculent content would leak out. A small-joint curette and a 2.9-mm motorized shaver (CONMED, USA) with the negative pressure device were alternately induced to remove the remaining tissues of the ganglion cyst. To confirm that the cyst had been debrided adequately, we subsequently inserted the arthroscope into the intraosseous cavity for a closer visual field (Fig. 5). Thorough cleaning of the cavity was achieved until the normal cancellous bone was exposed.

Bone grafting was performed in a patient whose cyst occupied half width of the affected bone on cross section to avoid bone collapse. A total of 9 patients in our study underwent autogenous cancellous $\mathrm{g}$ rafting, in which the maximum diameters of the IOGs were larger than $6.5 \mathrm{~mm}$. Bone grafts were harvested from the dorsal aspect of the distal radius. The graft was ground into small pieces and delivered into the cavity of the carpal bone using a cannular. An impaction grafting was achieved by pressing the bone fragments through the tube using a small tamping rod. It is important to note that water perfusion would wash away the graft; therefore, the water inlet of arthroscope must be turned off during bone grafting. 
Finally, for the unstable intercarpal joint, radiofrequency shrinkage was performed at the neutral position of the wrist. A bipolar radiofrequency was used to heat the ligament to simulate ligament tension. Radiofrequency instruments were introduced to the proximal and dorsal portion of the ligaments though radiocarpal portals and to the distal portion of the palmar and dorsal ligament through midcarpal portals. Careful attention was always paid to avoid cartilage damage and to keep the smooth outflow of the procedure, lowering the intra-articular temperature. It was confirmed that teeter totter sign was not observed when prying with the probe hook. However, thermal shrinkage of the lax ligaments must be performed after IOG excision to avoid secondary injury during surgeries.

The arthroscopic portals and the bone donor sites incision were closed after the wrist joints were thoroughly irrigated. The wrists were immobilized with a plaster in a neutral position.

\section{Rehabilitation}

Under analgesic treatment with pain medication, active movement immediately began after surgery for patients without bone graft. For patients with bone graft, a functional splint for the wrist was required for 3 weeks to avoid graft spillage, in which the fingers were left freely to facilitate the active motion of digital joints. From the fourth week, full ROM and strength exercise for the affected wrist were started to restore the wrist's full function. The hand and wrist function were assessed at the clinic every 3 weeks in the first 3 months and once every 6 months subsequently. Both imaging and functional outcomes were assessed at follow-up.

\section{Statistical analyses}

Values of VAS, ROM, grip strength, MWS, and DASH were expressed as mean \pm standard deviation. A comparative study between the preoperative and postoperative means was conducted using the paired-sample Student's t-test using the Statistical Product and Service Solutions (SPSS) version 21.0 statistical software (SPSS Inc., Chicago, IL, USA). A P value less than 0.05 was considered significant.

\section{Results}

Patients' mean age at the time of surgery was 35.5 years (range, 23-56 years), none of the patients had ever experienced wrist joint trauma, and a total of 8 patients were engaged in moderate to heavy manual labor. The duration of symptoms before surgery ranged from 10 to 43 months (median, 22 months). A total of 3 men and 11 women were included in the study. All patients were right-handed, of which 8 were affected. The lunate was affected in 5 patients, triquetrum in 5 patients, scaphoid in 2 patients, capitatum in 1 patient, and trapezium in 1 patient. The soft tissue ganglion cysts, which were occult and were diagnosed on MRI, coexisted in 5 patients. All patients experienced intercarpal joint instability, which was observed during operation, ranging from grade $₫$ to grade $\Downarrow$. The size (maximum diameters) of the intraosseous carpal ganglion cysts was $4.1 \pm 1.2 \mathrm{~mm}$. Based on pathologic findings, the ganglion cyst had a delicate wall of fibro-connective tissue with myxoid degeneration. Table 1 presents the detailed data of the patients' cohort. 
Table 1

Clinical Data of Patients With Intraosseous Ganglion Cysts

\begin{tabular}{|c|c|c|c|c|c|c|c|c|c|}
\hline Patient & $\begin{array}{l}\text { Age at } \\
\text { Surger } \\
\text { (y) }\end{array}$ & Sex & $\begin{array}{l}\text { Affected } \\
\text { Side/ } \\
\text { Dominance }\end{array}$ & $\begin{array}{l}\text { Affected } \\
\text { carpus }\end{array}$ & $\begin{array}{l}\text { Diameter } \\
(\mathrm{mm})\end{array}$ & $\begin{array}{l}\text { soft } \\
\text { tissue } \\
\text { ganglia } \\
\text { Cyst } \\
\text { coexist }\end{array}$ & $\begin{array}{l}\text { Geissler } \\
\text { Classification }\end{array}$ & Reappearance & $\begin{array}{l}\text { Follow- } \\
\text { Up Time } \\
\text { (months) }\end{array}$ \\
\hline 1 & 26 & Female & $\mathrm{L} / \mathrm{R}$ & Lunate & 3.6 & Yes & प & No & 23 \\
\hline 2 & 35 & Female & $\mathrm{R} / \mathrm{R}$ & Lunate & 4.2 & No & $\square$ & No & 34 \\
\hline 3 & 52 & Female & $\mathrm{L} / \mathrm{R}$ & Triquentral & 4.9 & No & $\square$ & No & 19 \\
\hline 4 & 34 & Female & $\mathrm{R} / \mathrm{R}$ & Scaphoid & 4.8 & Yes & $\square$ & No & 28 \\
\hline 5 & 36 & Male & $\mathrm{R} / \mathrm{R}$ & Lunate & 3.6 & No & $\square$ & No & 38 \\
\hline 6 & 31 & Female & $\mathrm{R} / \mathrm{R}$ & Trapezium & 2.8 & No & $\square$ & No & 32 \\
\hline 7 & 56 & Male & $\mathrm{R} / \mathrm{R}$ & Triquentral & 2.5 & Yes & $\square$ & No & 22 \\
\hline 8 & 23 & Female & $\mathrm{L} / \mathrm{R}$ & Capitatum & 5.8 & No & $\square$ & No & 29 \\
\hline 9 & 27 & Female & $\mathrm{L} / \mathrm{R}$ & Triquentral & 3.9 & Yes & $\square$ & No & 25 \\
\hline 10 & 33 & Female & $\mathrm{L} / \mathrm{R}$ & Lunate & 3.3 & No & $\square$ & No & 28 \\
\hline 11 & 40 & Male & $\mathrm{R} / \mathrm{R}$ & Scaphoid & 2.6 & No & $\square$ & No & 33 \\
\hline 12 & 42 & Female & $\mathrm{L} / \mathrm{R}$ & Lunate & 3.4 & No & $\square$ & No & 27 \\
\hline 13 & 35 & Female & $\mathrm{R} / \mathrm{R}$ & Triquentral & 6.5 & No & $\square$ & No & 23 \\
\hline 14 & 27 & Female & $\mathrm{R} / \mathrm{R}$ & Triquentral & 5.3 & Yes & $\square$ & No & 16 \\
\hline Mean & 35.5 & & & & 4.1 & & & & 27 \\
\hline SD & 9.5 & & & & 1.2 & & & & 6 \\
\hline
\end{tabular}

SD, Standard Deviation

The mean follow-up time was 27 months (range, 16-38 months). All patients experienced significant pain relief. VAS scores improved from an average preoperative level of 4.2 to 0.4 , and 9 of the patients did not experience pain. None of the patients experienced tenderness upon palpation or swelling. The average grip strength was $21.9 \mathrm{~kg}$ (range, $16-26 \mathrm{~kg}$ ) before surgery and increased to $25.9 \mathrm{~kg}$ (range, $21-37 \mathrm{~kg}$ ) after surgery $(P=.003)$. Wrist flexion and extension had no significant difference between pre-operation and post-operation, respectively $(P>.05)$.

Regarding the function evaluation, the DASH score improved from 25.3 to 7.6 , and the MWS increased from 56.4 to 87.1 on average. Both values were significantly better than that before surgery $(\mathrm{P}<.001, \mathrm{P}<.001)$. The DASH score was 0 in 2 patients. The highest DASH score was 16.7, which was observed in a middle-aged male construction worker; however, he returned to his previous work after a half-year sick leave. Postoperative imaging analysis revealed that the bone graft completely healed, and signs of cyst recurrence were not observed in all patients (Fig. 6). Bone donor sites were healed without resorption or hyperosteogenesis.

Scapholunate and lunotriquetral spaces were within normal limits $(<3 \mathrm{~mm})$, and carpal bone collapse was not observed. Table 2 presents the detailed results of the patients. 
Table 2

The detailed results of the patients

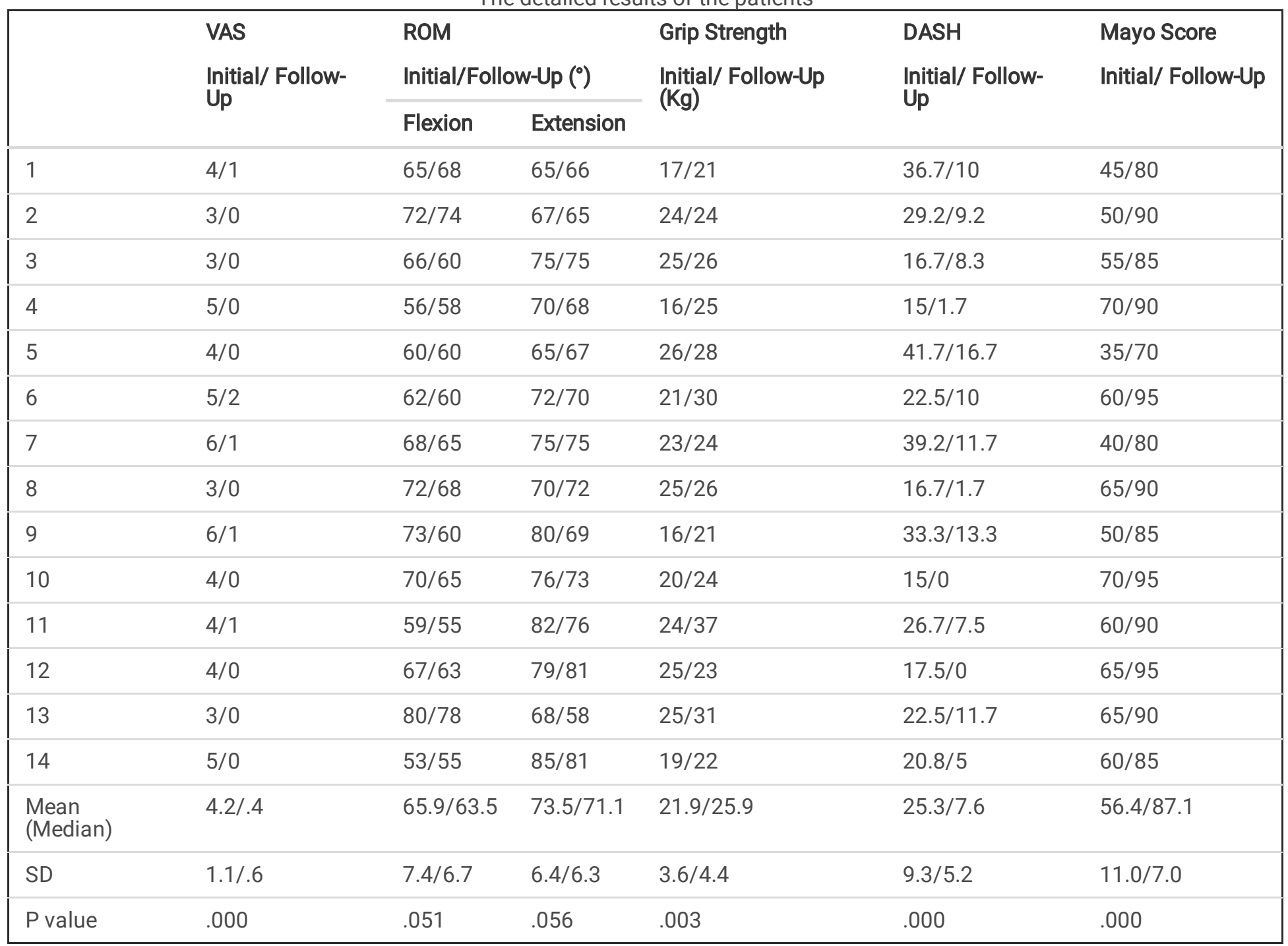

VAS, visual analog scale; ROM, ranges of motion; DASH, disabilities of the arm, shoulder, and hand.

Finally, 10 patients returned to their previous work and maintained their hand dominance, 3 performed a lighter work, and 1 retired. Complication or reoperation was not observed in all patients.

\section{Discussion}

IOGs of the carpal bones are common but rarely cause persistent pain and wrist stiffness. Different from degenerative cysts, most IOGs have a direct or indirect connection with the extraosseous ganglion cysts with the same origin (intrinsic or extrinsic ligaments). Nazerani et al. ${ }^{[14]}$ reported an anatomically gross soft tissue ganglion communicating with the lunate IOG through a defect on the posterior side of the lunate. Ashwood et al. ${ }^{[15]}$ noted that 7 out of their 8 patients had an extraosseous extension of the IOGs, but strategies performed to manage this extension were not mentioned in their study. The pathogenesis of these cysts remains unclear. There are some theories about the origins of these cysts including the following: traumatic mucoid degeneration of connective tissue, metaplasia of mesenchymal precursor cells, synovial herniation, and neoplasia. ${ }^{[7,16]}$ We believe that these lesions, both the intraosseous and extraosseous ganglion cysts, are observed as a result of the mucoid degeneration of the adjacent ligaments according to the histopathologic findings, including a thin wall with fibrous collagen and myxoid degeneration containing a clear viscous fluid that has high hyaluronic acid concentration. ${ }^{[4,17]}$ Histologically, Schrank et al. ${ }^{[18]}$ conducted a cadaveric study and furtherly proved that the IOGs were associated with the insertion of the degenerated ligaments, which were the extrinsic ligaments in $37.5 \%$ of their patients, and the intra-articular ligaments (scapholunate and lunotriquetral ligaments) in $52 \%$ of their patients. We 
found that the laxity of the ligaments was observed more frequently among these patients, relatively contributing to the partial symptoms.

Surgical intervention for IOGs will be introduced after a failure of conservative treatment, including either open exposure or minimally invasive method. Traditional open curettage with bone grafting has provided some successful experiences and lessons as well. Tham and Ireland ${ }^{[7]}$ treated 9 patients with 1 poor and 2 fair results due to pain at the scapholunate region, where the lesions originated from, with the possible occurrence of scapholunate instability. Waizenegger ${ }^{[16]}$ reported incomplete pain relief and work decrement for 6 patients, but reasons behind this finding were not explained in the study. With the development of the wrist arthroscopic technology, a minimally invasive procedure has been widely used in the field of wrist surgery. This minimally invasive approach irritates significantly less soft tissue; thus, the capsules and ligaments remain intact, reducing the risk of arthrofibrosis and damage to the vascular system of the carpal bones that might possibly lead to open exposure. ${ }^{[7,15,19]}$ Using an arthroscope, a complete and clear view of the joint could be achieved, subsequently treating the intra-articular lesions. Furthermore, concomitant morbidities such as extraosseous cysts and intercarpal joint instability can also be treated arthroscopically with a better esthetic result. Arthroscopic treatment for IOGs through small incisions has been used for approximately a decade since Ashwood first described its use ${ }^{[15]}$. They treated 8 patients with IOGs of the lunate, and the results were significant; pain scores, grip strength, ROM, and function scores of all patients improved. However, scapholunate or lunotriquetral joint stability was not assessed in their study, or the patients included in their study had isolated wrist IOGs without intercarpal instability.

Patients with wrist IOGs who were treated had frequently experienced intercarpal instability ranging from grade $\nabla$ to $\nabla$ according to Geissler's classification. Among the 45 patients in the study of Edwards et al., ${ }^{[17]}$ every patient with a wrist ganglion cyst had scapholunate joint laxity, with the highest grade of IV observed in 1 patient. Evaluating the arthroscopic treatment for patients who have IOGs combined with intercarpal joint instability is required. Previous studies had confirmed the effectiveness of radiofrequency shrinkage in modifying joint stability as a result of the thermally induced contraction of the capsules and ligaments.

[9-11,20-21] Arthroscopic procedure of thermal shrinkage using a bipolar radiofrequency probe was performed in our series to prevent further joint instability development, which is considered a potential source of wrist pain. Follow-up studies confirmed better results compared to several previous studies. Our study also suggested that the occult soft tissue ganglion cyst could coexist with carpal IOGs, considering that they had similar histopathologic features. However, the association between these two is still unclear. Therefore, surgeons should pay careful attention when dealing with patients with carpal IOGs and should determine whether wrist pain is associated with the carpal IOGs so that necessary treatment can be properly performed. On the contrary, the soft tissue ganglion cysts are frequently associated with the intercarpal ligaments, which is considered one of the reasons of wrist instability.

The present study has some limitations. First, this retrospective follow-up case study has no control group. Second, the sample size of the case group was relatively small; hence, a large-scale controlled study should be performed in the near future. Regarding the surgical technique, the learning curve for arthroscopic operation is long. Senior surgeons with sufficient knowledge on the wrist's anatomy are more likely to avoid cartilaginous and soft tissue complications. To minimize the complications of donor sites for bone grafting after the curettage of the IOGs, calcium phosphate bone cement injection is considered an alternative option. ${ }^{[22]}$

\section{Conclusion}

Arthroscopic treatment for symptomatic carpal bone IOGs combined with intercarpal joint occult instability, with completely intraosseous lesion excision and intercarpal ligament shrinking, is an effective and reliable method to improve their pain scores and wrist function.

\section{Abbreviations}

IOGs: Intraosseous ganglion cysts

ROM: Range of motion

VAS: Visual analog scale

DASH: Disabilities of the Arm, Shoulder, and Hand questionnaire 
MWS: Mayo Wrist Score

CT: Computed tomography

MRI: Magnetic resonance imaging

MCU: Midcarpal ulnar portal

MCR: Midcarpal radial portal

SPSS: Statistical Product and Service Solutions

\section{Declarations}

\section{Acknowledgements}

Not applicable.

\section{Funding}

This work was supported by Six Talent Peaks Project in Jiangsu Province (CN) with Grant Number: WSW-103, Wuxi Health and Family Planning Commission (CN) with Grant Number: MS201825囚Jiangsu Post-doctoral Research Funding Program (CN) with Grant Number: $2020 Z 359$.

\section{Availability of data and materials}

The datasets analyzed during the current study are available from the corresponding author on reasonable request.

\section{Author details}

Affiliations

1 Wuxi Ninth People's Hospital Affiliated to Soochow University, Wuxi, Jiangsu, 214062, China

2 Shangyu People's Hospital, Shangyu, Zhejiang, 312300, China

\section{Contributions}

GZ and ST contributed to the data analysis and interpretation and manuscript draft. JM is the lead surgeon of the present study and contributed to the study design and manuscript edit. QY enrolled the patients in the study, contributed to the data collection. The authors read and approved the final manuscript.

\section{Ethics approval and consent to participate}

This study was approved by the Ethics Committee of Wuxi Ninth People's Hospital Affiliated to Soochow University.

\section{Consent for publication}

Informed consent was obtained from all individual participants included in the study.

\section{Competing interests}

The authors declare that they have no competing interests.

\section{References}

1. Forthman CL, Segalman KA. Lesions and tumors of the carpus. Hand Clin 2016;22:435-46. 
2. Paparo F, Fabbro E, Piccazzo R, Revelli M, Ferrero G, Muda A, et al. Multimodality imaging of intraosseous ganglia of the wrist and their differential diagnosis. Radiol Med 2012;117:1355-73.

3. Edwards SG, Johansen JA. Prospective outcomes and associations of wrist ganglion cysts resected arthroscopically. J Hand Surg Am 2009;34:395-400.

4. Van den Dungen S, Marchesi S, Ezzedine R, Bindou D, Lorea P. Relationship between dorsal ganglion cysts of the wrist and intraosseous ganglion cysts of the carpal bones. Acta Orthop Belg 2005;71:535-9.

5. Mogan JV, Newberg AH, Davis PH. Intraosseous ganglion of the lunate. J Hand Surg 1981;6:61-3.

6. Schajowicz F, Clavel Sainz M, Slullitel JA. Juxta-articular bone cysts (intra-osseous ganglia). A clinicopathological study of eighty-eight cases. J Bone Joint Surg 1979;61:107-16.

7. Tham S, Ireland DCR. Intraosseous ganglion cyst of the lunate: diagnosis and management. J Hand Surg 1992;17: 429-32.

8. Fontaine C, Wavreille G, Aumar A, Bry R, Demondion X. Osseous vascular anatomy in the hand and wrist. Chir Main 2010;29:1120.

9. Coons DA, Barber FA. Thermal medial retinaculum shrinkage and lateral release for the treatment of recurrent patellar instability. Arthroscopy 2006;22:166-71.

10. Hill AM, Jones IT, Hansen U, Suri A, Sandison A, Moss J, et al. Treatment of ligament laxity by electrothermal shrinkage or surgical plication: a morphologic and mechanical comparison. J Shoulder Elbow Surg 2007;16:95-100.

11. Miniaci A, Codsi MJ. Thermal capsulorrhaphy for the treatment of shoulder instability. Am J Sports Med 2006;34:1356-63.

12. Geissler WB, Freeland AE, Savoie FH, McIntyre LW, Whipple TL. Intracarpal soft-tissue lesions associated with an intra-articular fracture of the distal end of the radius. J Bone Joint Surg 1996;78:357-65.

13. Osterman AL, Raphael J. Arthroscopic resection of dorsal ganglion of the wrist. Hand Clin 1995;11:7-12.

14. Nazerani S, Ebrahimpour A, Najafı A, Shams Koushki E. Intraosseous ganglion cyst of the lunate. Trauma Mon 2012;16:198200.

15. Ashwood N, Bain GI. Arthroscopically assisted treatment of intraosseous ganglions of the lunate: a new technique. J Hand Surg Am 2003;28:62-8.

16. Waizenegger M. Intraosseous ganglia of carpal bones. J Hand Surg 1993;18:350-5.

17. Bain GI , Turner PC , Ashwood N. Arthroscopically assisted treatment of intraosseous ganglions of the lunate. Tech Hand Up Extrem Surg 2008;12:202-7.

18. Schrank C, Meirer R, Stäbler A, Nerlich A, Reiser M, Putz R. Morphology and topography of intraosseous ganglion cysts in the carpus: an anatomic, histopathologic, and magnetic resonance imaging correlation study. J Hand Surg Am 2003;28:52-61.

19. Cerlier A, Gay AM, Levadoux M. Arthroscopic Treatment of Intraosseous Ganglion Cyst of the Lunate Bone. Arthrosc Tech 2015;4:513-8.

20. Darlis NA, Weiser RW, Sotereanos DG. Partial scapholunate ligament injuries treated with arthroscopic debridement and thermal shrinkage. J Hand Surg Am 2005;30:908-14.

21. Farng $E$, Hunt $S A$, Rose DJ, Sherman $\mathrm{OH}$. Anterior cruciate ligament radiofrequency thermal shrinkage: a short-term follow-up. Arthroscopy 2005;21:1027-33.

22. Yajima H, Murata K, Kawamura K, Kawate K, Takakura Y. Treatment of intraosseous ganglia and bone cysts of the carpal bones with injectable calcium phosphate bone cement. Hand Surg 2008;13:167-73.

\section{Figures}




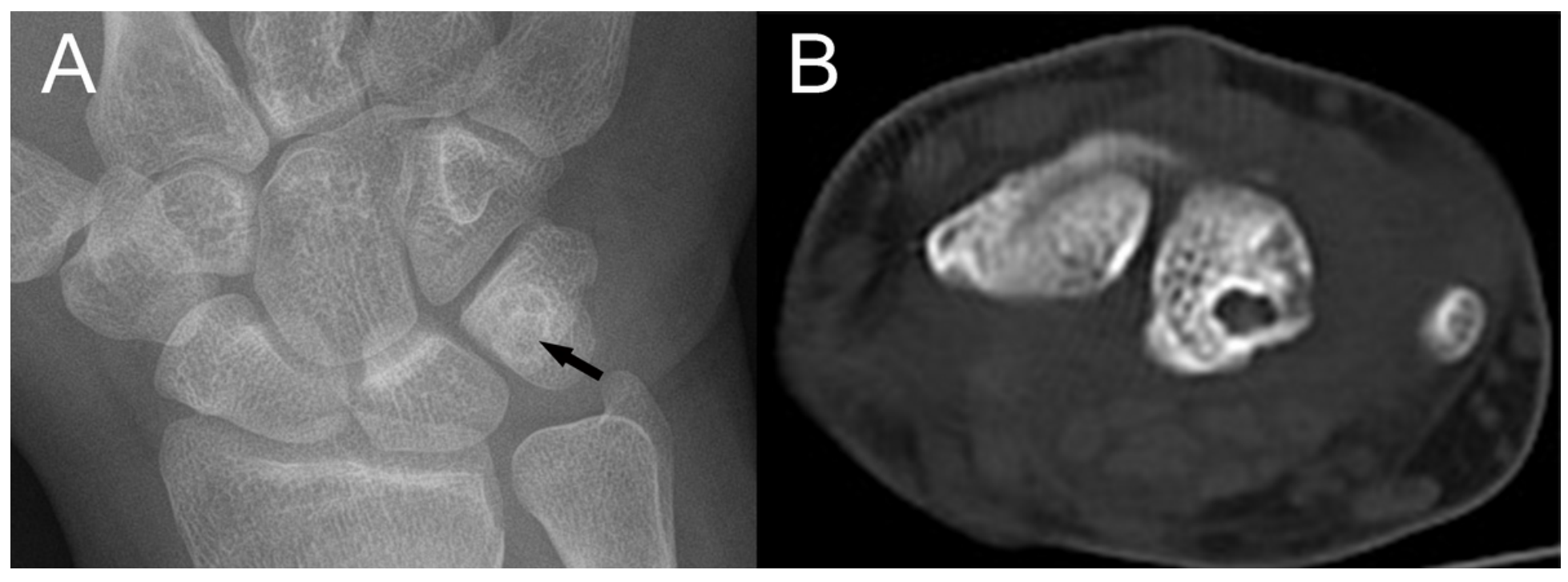

\section{Figure 1}

Typical X-ray imaging of the intraosseous ganglion cysts. (A) A multilocular cyst (arrow) within the triquetrum. (B) An eccentrically located radiolucent lesion with a thin sclerotic margin within the lunate. 


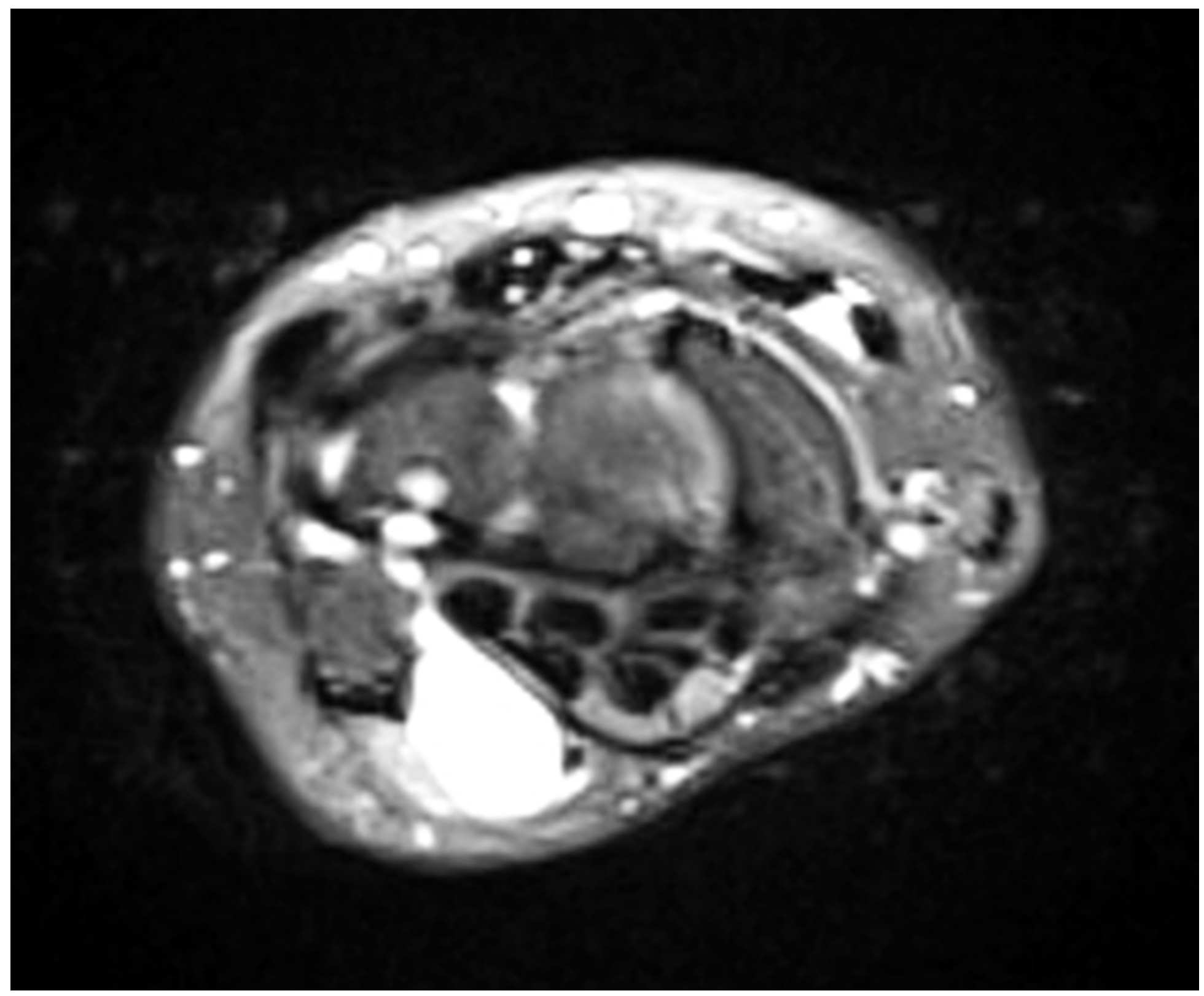

\section{Figure 2}

Magnetic resonance imaging revealing the communication between the intraosseous ganglion cyst and the triquetrum with the giant palmar cyst, resulting in ulnar nerve compression. 


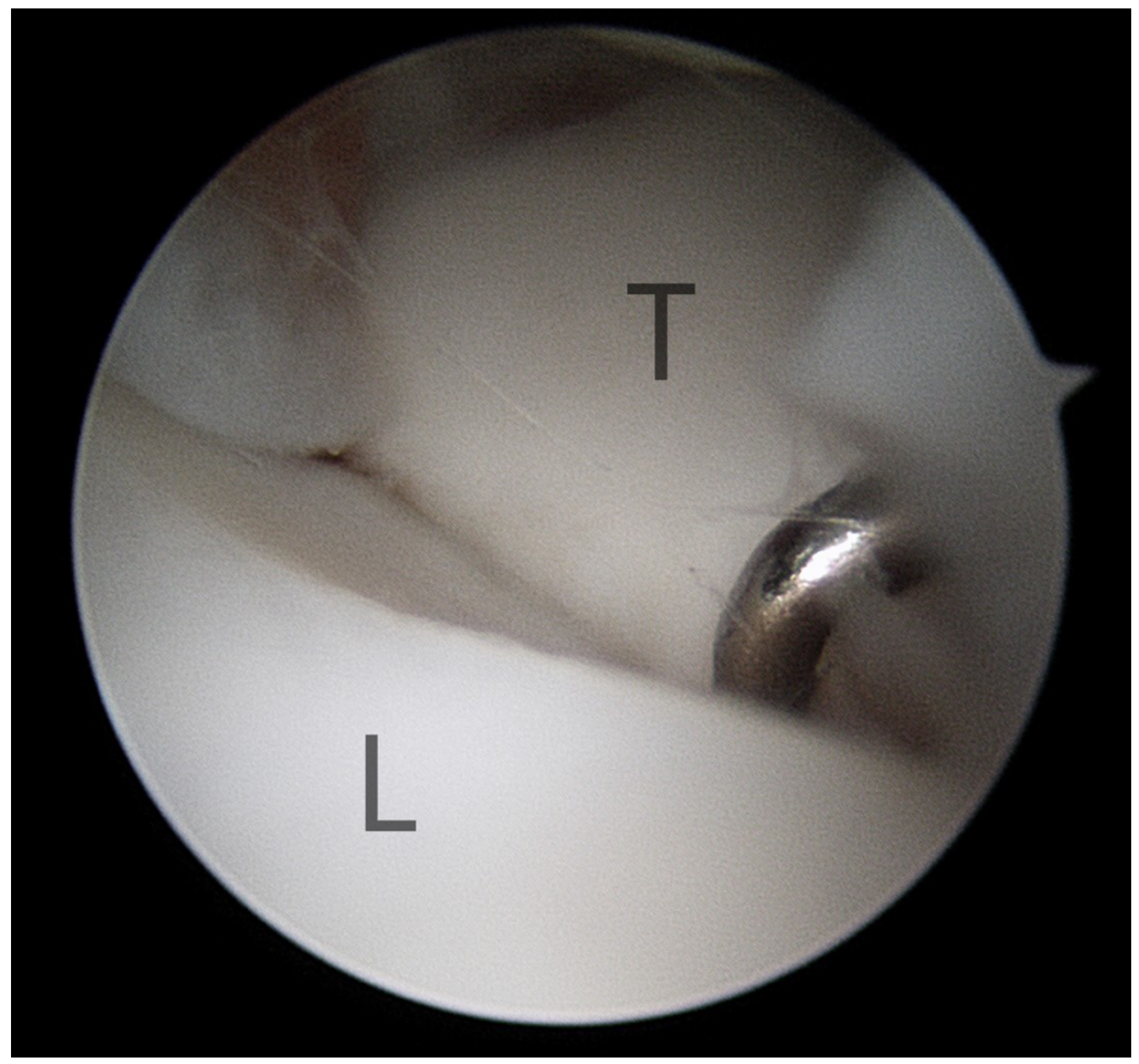

\section{Figure 3}

A probe was used via the midcarpal ulnar portal to detect the stability between the lunate and the triquetrum. Step-off of the carpal alignment was observed, and the probe could be passed through the gap between the lunate and triquetrum. A grade III Geissler classification was observed for this patient. 


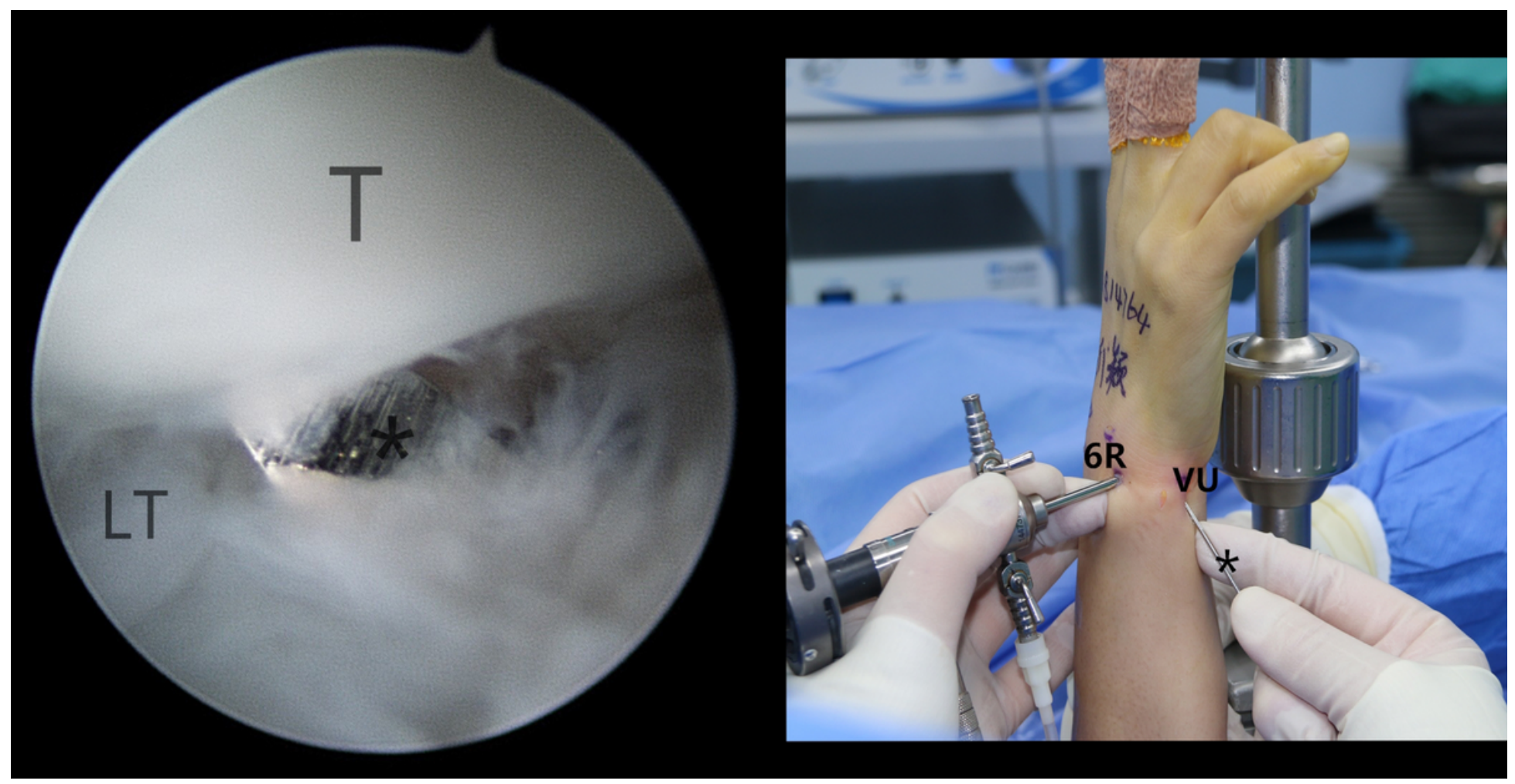

\section{Figure 4}

Arthroscopic drilling of the triquetrum. The arthroscope was placed in the 6R portal, and a Kirschner wire (asterisk) was used for drilling through the volar ulnar portal. The arthroscopic window showed the placement of the drill on the nonarticular volar triquetrum surface, just on the ulnar side of the lunotriquetral ligament.

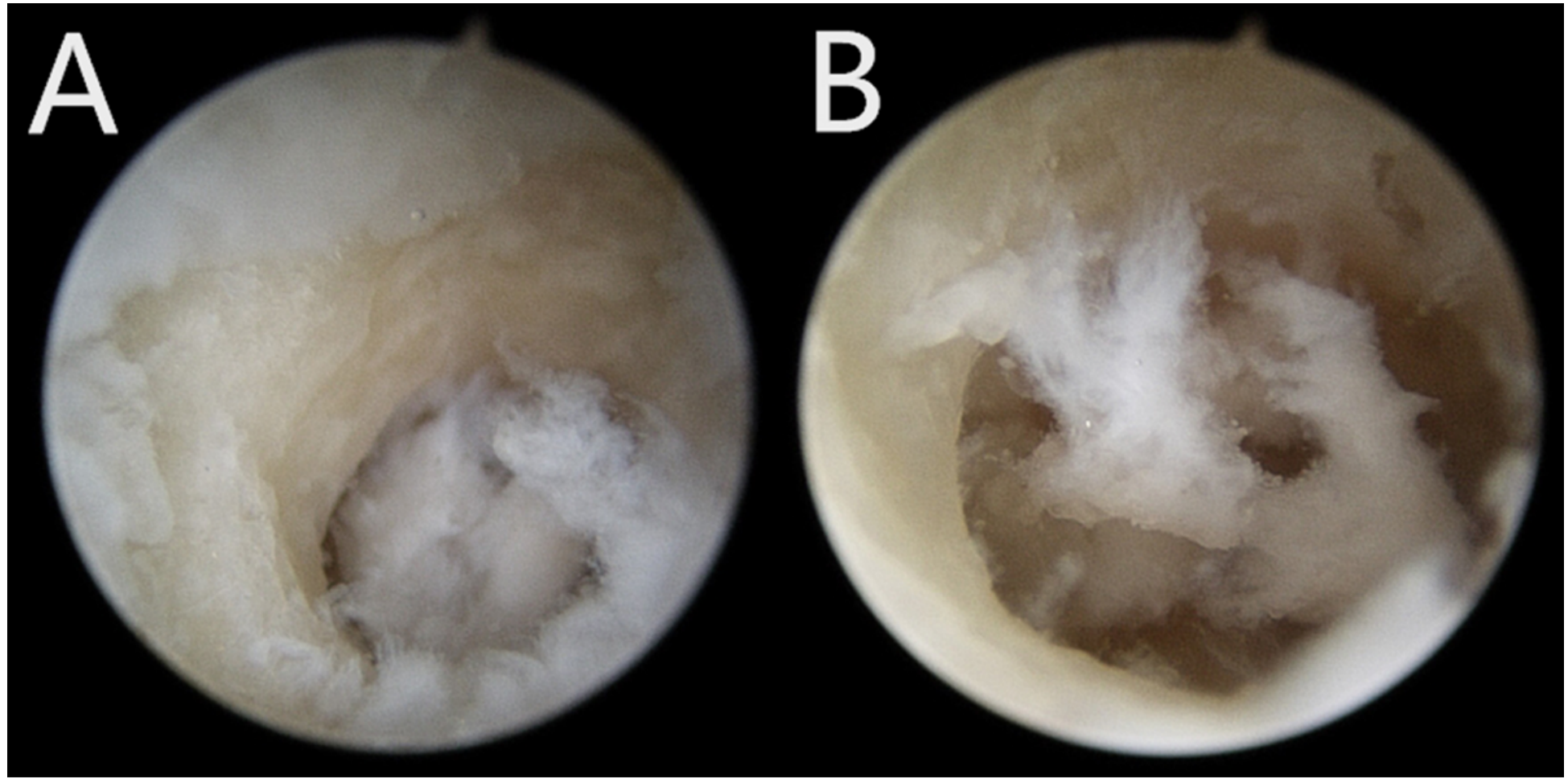

\section{Figure 5}

A direct cystoscopic view of the intraosseous ganglion cyst was obtained by switching the operation portal and observation portal. (A) The ganglion could be easily observed at the bottom of the ostial hole. (B) During debridement, a mixture of soft tissue and 


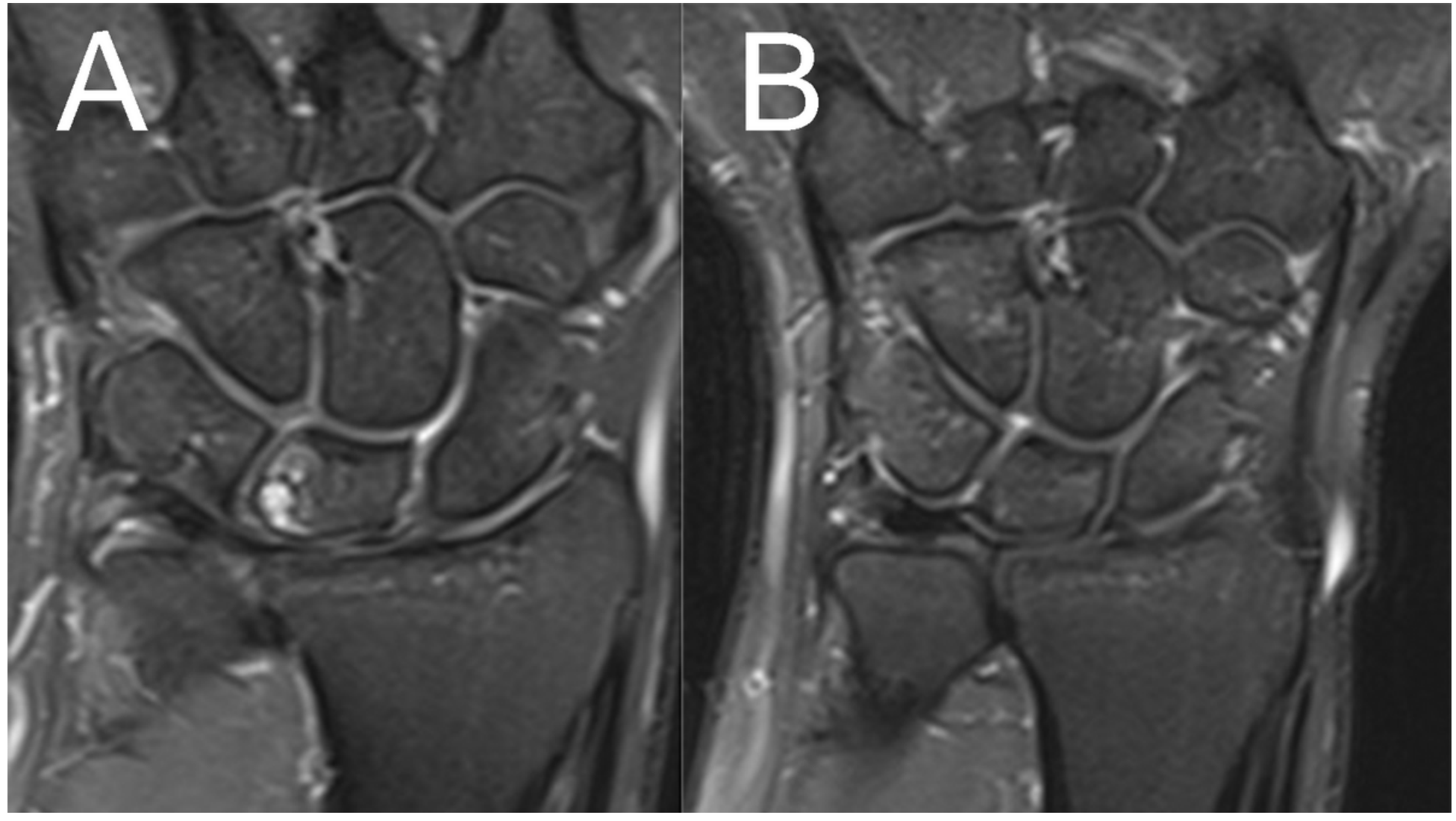

\section{Figure 6}

Magnetic resonance imaging revealing a healed fracture of the lunate with no recurrence of the intraosseous ganglion cyst. (A) Preoperative imaging after the symptoms had lasted for 20 months. (B) Postoperative imaging at 6-month follow-up. 